\title{
An Analysis on the Automobile Interior Assembly Line Balancing Based on eM-plant
}

\author{
Shuang Liu \\ Kunming University of Science and Technology \\ Kunming, China \\ Sibao Jiang \\ Kunming University of Science and Technology \\ Kunming, China
}

\begin{abstract}
In this paper, the virtual environment of automobile interior assembly line is built by object-oriented modeling technology, aim at the problem of unreasonable processes, overmuch work-in-process (WIP) and long production cycle etc. in the assembly line of automobile manufacturing enterprises. The simulation software eM-plant is used to discover the problems of production line balancing and bottleneck by simulating, collecting simulation data and analyzing simulation results in this paper, so that the overall efficiency of automobile interior assembly line will be improved, the assembly activities will be more smooth and efficient operation. And a reference for automobile manufacturing enterprise on-site management will be provided by the analysis results.
\end{abstract}

Keywords-Automobile interior assembly line, EM-plant, Simulation, Bottleneck

\section{INTRODUCTION}

With the fast changeable market demand and the development of enterprises, the problems of how to improve the overall efficiency of production lines, reduce the number of work-in-process (WIP), and the pursuit of simultaneous production in assembly line production mode are taken more and more seriously. Generally, the level of an assembly line balance is evaluated by balance ratio which is a quantifiable index in enterprise production. To some extent, the enterprise equipment utilization and the improving of production line's capacity are decided by balance ratio[1].

Both production efficiency of automobile manufacturing industry and competitiveness of enterprises are affected by the level of an automobile assembly line balance. There have been many simulation studies about automobile assembly line at home and abroad, a simulation model of automobile assembly workshop was built according to the modeling requirements of logistics simulation software ProModel in literature[2], the logistics of automobile assembly workshop were modeled and simulated, and the method of the ESHLEP-N model changed to assembly workshop Flexsim model was studied based on simulation software Flexsim in literature[3], the stations' simulation object model and control logic in part of chassis section and package section were built on platform of digital

\author{
Kaihu Hou \\ Kunming University of Science and Technology \\ Kunming, China
}

factory software eM-Power in literature[4], the simulation research of multi-rules and multi-objective was done for the balancing problem of linear and U-type assembly line in literature[5], mixed model assembly line was studied by using simulation annealing algorithm in literature[6].

The simulation software eM-plant is used in this paper based on a study of automobile interior assembly line in one automobile manufacturing enterprise. Because the software is based on object-oriented modeling theory, so a lot of production equipment unit and logistics device model libraries are provided, and a lot of simulation control strategy is also provided. The SimTalk language embedded in eM-plant can be used flexibly for planning, simulation and optimization manufacturing enterprises, the production system and process technology. The index of production system, such as productivity, WIP level, the equipment utilization, workers load balance condition and so on can be analyzed and optimized in eM-plant environment by users[7-8].

\section{SYSTEM DESCRIPTION}

\section{A. Sample Selection}

An interior assembly line in $\mathrm{X}$ automobile manufacturing enterprise is studied in this paper, and an interior assembly flow chart of one automobile produced in this enterprise is showed in Figure.1, there are 23 processes in all, which are encoded as process1-process 23 . The automobile's body is transported to the assembly line after coating, and then respectively through each process.

A lot of data is needed for support in computer simulation, the processing time of process1-process 23 in automobile interior assembly line is got by collecting, the time is shown as Tab.1(unit: s).

As the formula is used,

$$
\mathrm{CT}=\frac{\mathrm{T}_{\mathrm{W}}}{\mathrm{Q}}
$$

The average beat can be seen as follows:

$$
\mathrm{CT}=\frac{24 \times 3600}{350} \approx 247 \mathrm{~s}
$$


As is shown in Tab.1, some measures should be taken to shorten the processing time of these processes, because the processing time of process 13 and process 14 is more than the $\mathrm{CT}$. Then, the following formula is used,

$$
P=\frac{\sum_{j=1}^{n} T_{j}}{n \times \max \left(T_{j}\right)} \times 100 \%
$$

The formula (2) is used to calculate the balancing rate of production line, the calculation result is

$$
P=\frac{\sum_{j=1}^{23} 191+\ldots+138}{23 \times 280} \times 100 \% \approx 65.31 \%
$$

Therefore, the simulation analysis are need to adjust this unbalanced production line because of $65.31 \%$ is not a large data.

\section{B System assumptions}

Because the system is affected by many random factors in the assembly process, such as arriving time of automobile's body, assembly time, equipment maintenance, equipment stoppage, etc., so assumptions are made as follows:

1) The arriving time of automobile's body subject to the distribution of Normal $(3,1)$ minutes, the normal distribution is accorded to the processing time of each process;

2) The FIFO(First In First Out) is used in all processes, and each process has the same number of operating workers;

3) All components are no shortage of material;

4) 24-hour production in this enterprise, simulation of 30 days.

\section{CONSTRUCTION OF SYSTEM MODEL}

Automobile interior assembly line can be considered as a series of discrete event, logistics system, information processing and separation of decision control behavior can be achieved by using object-oriented simulation modeling framework which is a powerful tool for discrete manufacturing system modeling, and through describing the object characteristic, object behavior and relationships of system[9].

This system is composed of 23 processes according to the flow chart of automobile interior assembly line. Five kinds of basic object are included for the interior assembly modeling, there are entity class, information class, control class, process analysis class and result class. Each basic object is defined in MainFrame of simulation software eM-plant, and the properties of eM-Plant objects are set, such as name, interval, processing time, etc. All objects are connected according to the flow chart of automobile interior assembly line after the properties of objects are set well, as shown in Figure.2.

In this system, Finaltablefile and tongji two tables are used to record system performance evaluation parameters. Init 、 Reset 、 EndSim 、 CollectData and FinalStat five
Method objects which have eM-Plant's own simulation language SimTalk programming are used to control the operation of assembly line. The part of program statements is as follows:

is

local tab : table ;

do

Throughput :=Throughput +1 ;

tab.create;

@.statistics(tab);

Finaltablefile[1,Simulation_times]:= Simulation_times;

Finaltablefile[2,Simulation_times]:=Throughput;

Finaltablefile[3,Simulation times]:=Source.numin-

Drain.numin;

end;

\section{SimUlation ANALYSIS}

Run the simulation model, bottleneck analysis is done by Chart and BottleneckAnalyzer, as shown in Figure. 3 and Figure. 4 below.

As is shown in Figure. 3 and Figure.4, the working time of A13-A14 processes is more than others, the blocked time of A01-A13 processes which almost have no waiting time is more than other processes, and the waiting time of A14-A23 is too much. Therefore, this interior assembly line of which A13 and A14 processes are bottleneck process is imbalance, the interior assembly line should be adjusted.

\section{ADJUSTING PRODUCTION LINE BALANCING}

As is shown in Figure.3, that the working time of A06 and A21 processes is the least, the working time of A13 and A14 processes is too much, while the number of operating workers is same in each process, so the operating workers of A06 and A21 processes should be mobilized properly to A13 and A14 processes for balancing waiting time and working time of each process; Changing the processing time or adding buffer to reduce congestion; A22 and A23 processes are combined together to reduce the waiting time of $\mathrm{A} 23$ process.

Adjusted simulation results of this interior assembly line are shown in Figure.5 and Figure.6. The results show that the simulation system has been optimized to some extent, such as the efficiency of each process is increased, while waiting time and blocked time are reduced. However, the interior assembly line should be made further adjustments in follow-up work because of waiting and blocked phenomenon is still existed in some processes.

The following formula is used by referencing Tab.2,

$$
\mathrm{P}=\frac{\sum_{\mathrm{j}=1}^{\mathrm{n}} \mathrm{T}_{\mathrm{j}}}{\mathrm{n} \times \max \left(\mathrm{T}_{\mathrm{j}}\right)} \times 100 \%
$$
follows:

The balancing rate of production line is calculated as 


$$
\mathrm{P}=\frac{\sum_{\mathrm{j}=1}^{22} 191+\ldots+233}{22 \times 233} \times 100 \% \approx 78.38 \%
$$

Therefore, the balancing rate of production line is improved and the throughput is increased because of the data $78.38 \%$ is much larger than the original rate of $65.31 \%$.

\section{CONCLUSION}

Collecting and analyzing simulation data are done in this simulation system of automobile interior assembly line. Interior assembly line is optimized by finding bottleneck process and suggesting improvements, so that a lot of material resources are saved, the waste of money in physical assembly line adjustment is reduced, besides that the overall efficiency of automobile interior assembly line is improved, the assembly activities would be more smooth and efficient operation, a reference for distributing operating time of workers reasonably and planning assembly process is provided as scientific basis.

\section{ACKNOWLEDGEMENTS}

My heartfelt gratitude to my tutor Kaihu Hou Professor and my classmate Sibao Jiang who helped me complete the paper and gave me some invaluable guidance and inspiration. Special thanks for the project support: Yunnan Province Technology Innovation Program(Program Number: 2008AA011).

\section{REFERENCES}

[1] WU Xiao-yan. Study on Balancing of assembly line [D]. Shanghai: Shanghai Jiao Tong University, Dec 2007, pp.1-2.

[2] LI Bo; WANG Jun. Modeling and Simulation of a Truck Assembly Line [J]. Journal of University of Electronic Science and Technology of China, Vol.37 No.5, Sep 2008, pp. 789-800.

[3] XU Chen. Study on Logistics Modeling and Simulation of the Automobile Assembly Shop Based on Flexsim Platform [D].Shandong University, May 2008, pp.4-5.

[4] CAO Zhen-xin; ZHU Yun-long; LI Fu-ming. Research on dynamic planning and simulation optimization of mixed model general automobile assembly lines [J]. Computer Integrated Manufacturing Systems, Vol.12 No.4, Apr 2006, pp. 526-532.

[5] ADIL B. Multi-rule multi-objective simulated annealing algorithm for straight and $U$ type assembly line balancing problems $[\mathrm{J}]$.Journal of Intelligent Manufacturing,Vol.17 No.2, 2006, pp.217-232.

[6] KIM Ho-Gyun; CHO Hyung-Soo. Sequencing in a mixed-model final assembly line with three goals: Simulated annealing approach[J].International Journal of Industrial Engineering: Theory Applications and Practice, Vol.10 No.4, 2003, pp. 607-613.

[7] WANG Zhi-jun. Study on Simulation and Modeling Technology of Automobile Rear-Axle Assembly Line System Based on Em-Plant [J]. Equipment Manufacturing Technology, No.8, 2009, pp. 13-15.

[8] YAO Hai-feng; FENG Xun-sheng; GUO Ding-jun. Simulation Study on Balancing Technology of Automobile Spare Parts Production Line Using eM - plant [J]. Logistics Technology, No.219, Jun 2010, pp. 114-117.

[9] YU Jun; FAN Liu-qun; MA Yu-min. Research on Pulling Production Simulation Based on eM-Plant[J].Computer Simulation, Vol.24 No.5, May 2007, pp.253-255.

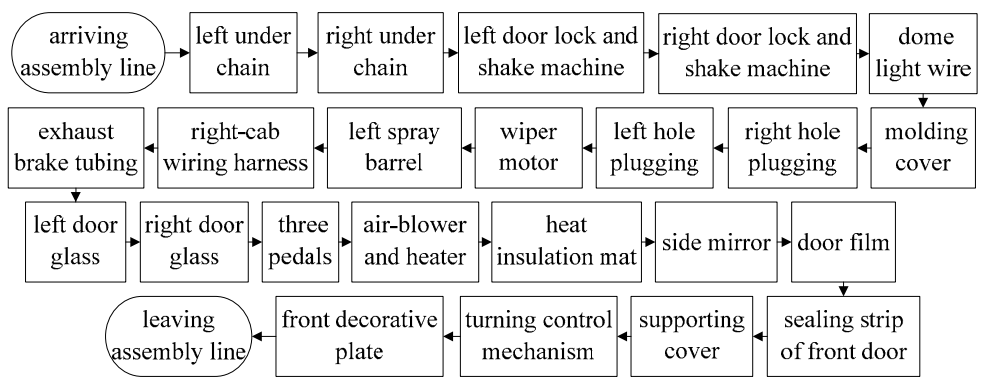

Figure 1. Flow chart of automobile interior assembly line

TABLE I. TABLE OF PROCESSING TIME

\begin{tabular}{|c|c|c|c|c|c|c|c|}
\hline Process & time (s) & Process & time (s) & Process & time (s) & Process & time (s) \\
\hline 1 & 191 & 7 & 181 & 13 & 265 & 19 & 173 \\
\hline 2 & 186 & 8 & 200 & 14 & 280 & 20 & 173 \\
\hline 3 & 198 & 9 & 154 & 15 & 158 & 21 & 161 \\
\hline 4 & 198 & 10 & 172 & 16 & 155 & 22 & 233 \\
\hline 5 & 168 & 11 & 194 & 17 & 214 & 23 & 138 \\
\hline 6 & 105 & 12 & 144 & 18 & 165 & & \\
\hline
\end{tabular}




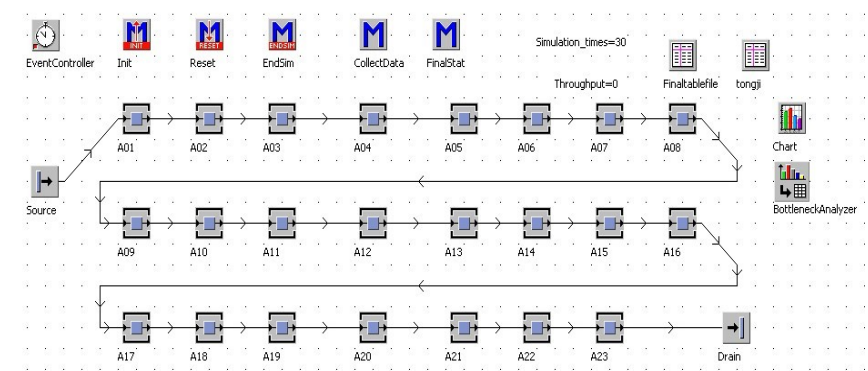

Figure 2. Simulation model of automobile interior assembly line

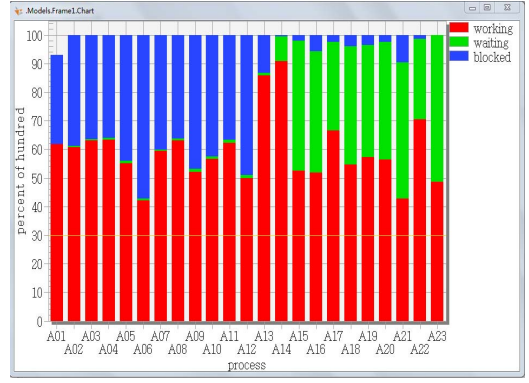

Figure 3. Working status of each process

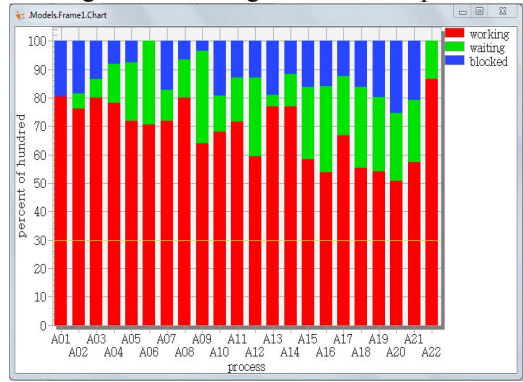

Figure 5. Adjusted working status

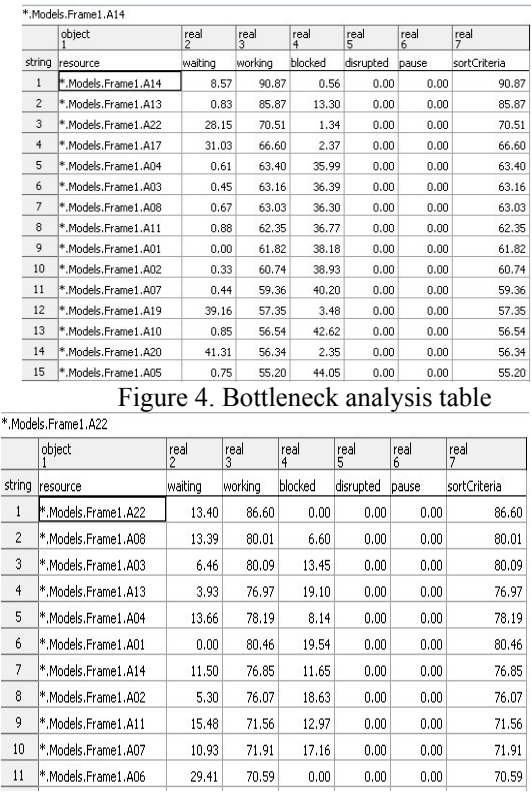

Figure 6. Adjusted bottleneck analysis table

TABLE II. TABLE OF OPTIMIZED PROCESSING TIME

\begin{tabular}{|c|c|c|c|c|c|c|c|}
\hline Process & time (s) & Process & time (s) & Process & time (s) & Process & time (s) \\
\hline 1 & 191 & 7 & 181 & 13 & 215 & 19 & 173 \\
\hline 2 & 186 & 8 & 200 & 14 & 220 & 20 & 173 \\
\hline 3 & 198 & 9 & 154 & 15 & 158 & 21 & 161 \\
\hline 4 & 198 & 10 & 172 & 16 & 155 & 22 & 233 \\
\hline 5 & 168 & 11 & 194 & 17 & 214 & & \\
\hline 6 & 165 & 12 & 144 & 18 & 165 & & \\
\hline
\end{tabular}

